\title{
ANALYSIS OF ASSESSMENT TESTS IN JOB APPLICATIONS TO LOGISTICS SECTOR
}

\author{
DOI: 10.17261/Pressacademia.2019.1085 \\ PAP- V.9-2019(32)-p.160-165
}

Filiz Eren ${ }^{1}$, A. Murat Koseoglu ${ }^{2}$

${ }^{1}$ Istanbul University, Cerrahpaşa Avcılar Kampüsü, Avcılar, İstanbul, Turkey.

filiz.eren@yaho.com.tr, ORCID: 0000-0002-4356-1049

${ }^{2}$ Okan University, Tuzla Campus, Istanbul, Turkey.

murat.koseoglu@okan.edu.tr; ORCID: 0000-0003-4169-3678

To cite this document

Eren, F., Koeseoglu, A.M., (2019). Analysis of assessment tests in job applications to logistics sector. PressAcademia Procedia (PAP), V.9, p.160-165

Permemant link to this document: $h$ ttp://doi.org/10.17261/Pressacademia.2019.1085

Copyright: Published by PressAcademia and limited licenced re-use rights only.

\section{ABSTRACT}

Purpose- The purpose of this study is to determine the dominant character among the assessment tests applied in the logistic sector job applications.

Method- In the scope of the research, 600 candidates' personality inventory tests examined that applied to a logistics company in 2018.

Findings- Four main characters have emerged at the end of examined personality inventory tests. These character types are $D$ (dominance), I (influence), S (steadiness), and C (conscientiousness). The most weighted character type among these character types is C (conscientiousness).

Conclusion- The personality inventory tests of the applicants and the employed personnel in the logistics sector were examined and it was determined that the character type $\mathrm{C}$ (conscientiousness) is dominant. This result enables us to have prior knowledge about the logistics sector employees. The candidates with this main character type have a reliable, detailed, careful and systematic structure. They exhibit a high concentration and a calm working discipline while doing their work. These characteristics fit the needs of logistics sector.

Keywords: Assessment tests, human resources, logistics, staffing,

JEL Codes: 015, M51, M54

\section{LOJISTiK SEKTÖRÜ iş BAŞVURULARINDA DEĞERLENDIRME TESTLERi ANALizi}

\section{ÖZET}

Amaç- Bu çalışma lojistik sektörü iş başvurularında yapılan değerlendirme testleri sonucunda hangi karakter tipinin baskın olduğunun tespit edilmesi amacıyla yapılmıştır.

Yöntem- Araştırma kapsamında bir lojistik firmasında 2018 yılı içerisinde lojistik sektöründe çalışmak için başvuru yapan 600 adaya uygulanan kişilik envanteri testleri incelenmiştir.

Bulgular- İncelenen kişilik envanter testleri sonucunda ortaya 4 ana karakter çıkmıştır. Bu karakter tipleri Dominant, İz Bırakan, Sadık ve Ciddi'dir.

Sonuç- Lojistik sektörüne başvuran adayların ve işe alınan personelin kişilik envanteri testleri incelendiğinde özellikle "Ciddi" ana karakter tipinin baskın olduğu saptanmıştır. Ciddi ana karakteri, lojistik sektörü çalışanları hakkında ön bilgiye sahip olmamızı sağlar. Bu ana karakter tipine sahip adaylar, güvenilen, itinalı, detaycı, dikkatli ve sistemli bir yapıya sahiptir. İşlerini yaparken yüksek konsantrasyon ve soğukkanlı bir çalışma disiplini sergilerler. Bu özellikler Lojistik sektörünün iş ihtiyaçları ile örtüşmektedir.

Anahtar Kelimeler: Insan kaynakları, işe alım, kişilik testleri, lojistik

JEL Kodları: 015, M51, M54

\section{GiRiş}

Bir işletmenin işgücü talebi; işletmede mevcut işgücü arzından büyük olduğunda personel açığı ortaya çıkar. Yeni faaliyet ve yatırımlara girişmek; işletmenin büyümesi, işten ayrılan veya işten çıkarılanların olması gibi nedenlerle işletmede personel açığı ortaya çıkar. Personel seçimi yapılırken kullanılan yöntemlerden biri olan işe alım testleri, özellikle doğru personelin işe alınmasında önemli bir role sahiptir. Bu 
testlerin yapılmasının sebebi, işgörenin niteliklerini ortaya çıkarmak değil, işgören ile tanımlı iş arasındaki farklılıkları minimize etmektir. Testlerin yapılması; haksızıkları önler, mülakatçılara rehber olur, hızlı sonuç verir, hata oranını minimize eder, arşivlenebilir. Personel seçme ve yerleştirmede kullanıldığı gibi, eğitim ihtiyaçlarının belirlenmesinde ve terfi-tayin-rotasyon süreçlerinde işveren yol gösterir.

\section{LITERATÜR TARAMASI}

\subsection{Lojistik Kavramı}

Lojistik tarihte orduların ihtiyacını karşılamak amacıyla oluşturulmuş bir organizasyon iken giderek büyüyen sanayi unsurlarının birbirleriyle ve ekonominin bütünüyle; hammadde elde edilmesinden nihai tüketiciye kadar gelen aşamalarda stoklama, kalitenin korunması, teknik destek gibi farklı etmenleri de içine almak zorunda kalmıştır. (Gümüş, 2009.)

TDK güncel Türkçe sözlüğüne göre lojistik; “Kişilerin ihtiyaçlarını karşılamak üzere her türlü ürünün, hizmetin ve bilgi akışının çıkış noktasından varış noktasına kadar taşınmasının etkili ve verimli bir biçimde planlanması ve uygulanması" olarak tanımlanmıştır. (http://www.tdk.gov.tr, Erişim: 12.04.2019)

Tedarik Zinciri Yönetimi Profesyonelleri Konseyi (CSCMP: Council of Supply Chain Management Professional), Lojistik Yönetimini: “Müşteri ihtiyaçlarını karşılamak üzere her türlü ürün, servis hizmeti ve bilgi akışının, başlangıç noktasından (kaynağından), tüketildiği son noktaya (nihai tüketici) kadar olan tedarik zinciri içindeki hareketinin etkili ve verimli şekilde planlanması, uygulanması, taşınması, depolanması ve kontrol altında tutulması hizmeti" olarak tanımlanmaktadır.

“Lojistik kavramı; hammaddenin ilk kaynağından tedarik edilmesi işleminden itibaren, müşteri memnuniyetinin sağlandığı ana kadar içinden geçilen tüm süreçleri kapsamaktadır. Bu kapsam ışığında gerçekleştirilen işlemler ise lojistik faaliyetlerdir." (Sezen ve Gök, 2004, aktaran Acar ve Köseoğlu, 2016, s. 4)

“Müşteri istek ve ihtiyaçlarına uygun olarak, ürün, hizmet ve bilgi akışının, başlangıç noktasından, tüketildiği noktaya kadar tedarik zinciri içindeki hareketinin etkin, verimli olarak gerçekleştirilmesini sağlayan lojistik taşıma, dağıtım, stok yönetimi gibi dağıtım sürecinde gerçekleştirilen, ürüne katma değer sağlayan birbiriyle ilişkili işlevleri kapsamaktadır." (Alkan ve Erdal, 2007, Küçük, 2011, aktaran Acar ve Köseoğlu, 2016, s. 1).

\subsection{Insan Kaynakları}

18.yüzyılda tohumları atılan ve 19.yüzyılda giderek hızlanan sanayi devrimi, ekonomiye ve üretime farklı boyutlar kazandırırken insanların çalışma ve yaşam şekillerini de kökten değiştirdi. Sanayi devriminin ilk aşamalarında insan faktörünü gözetmeyen, üretim ve kara aşırı önem veren bir anlayış sözkonusu iken 20.yy boyunca yaşanan gelişmeler ve farklı kültürlerin ve sosyal tabakaların sanayileşmeye katılması ile Personel Yönetimi anlayışı şekillenmiştir. (Yarımkaya, 2011)

2.Dünya Savaşı́nı izleyen yıllarda ABD öncülüğünde başlayıp Avrupa'yı da içine alan yeni insan kaynakları perspektifleri ortaya çıktı. Bugüne kadar insanın etkin bir faktör olarak geride kaldığı tüm düşünceler konjonktürel etmenlerin de yardımıyla sosyolojik ve psikolojik bir hal almaya başlar. Sadece iş, çalışma psikolojisi, eğitim ve endüstriyel ilişkiler açısından bakışın yeterli olmadığı görülmüş, teknolojinin gelişmesi, rekabetin artması ile kaliteli işgören ihtiyacı artmıştır. (Tunçer, 2012)

“80’li yıllara kadar "Fordist-Taylorist” paradigma tarafından bir maliyet unsuru olarak görülen insan kaynakları/örgütteki insan unsuru küreselleşme, uluslararası alana taşınan rekabet, gelişen teknolojiler, değişen üretim ve yönetim modelleri ile birlikte stratejik bir önem kazanmıştır. İnsan kaynakları yönetiminin bu stratejik öneminin ardında, örgüt performansına yaptığı katkının ve örgüte sağladığı rekabet üstünlüğünün olduğunu söyleyebiliriz." (Bayat, 2008).

İnsan Kaynakları Yönetimi, organizasyonel ve çevresel ortamda insan kaynaklarının örgüte, kişiye ve topluma faydalı olacak şekilde, kanunlara da uyularak etkili yönetilmesini sağlayan çalışmaların tümü olarak tanımlanabilir. Günümüzde İnsan Kaynakları Yönetimi ifadesi, personel yönetiminin değişen niteliğini anlatmak için kullanılır. (Sadullah, 2013)

\subsection{DISC Kişilik Envanter Testi}

DISC teorisi ilk olarak 1928 yılında Dr. William Moultan Marston tarafından "Emotions of Normal People" - "Normal Kişilerin Duyguları" kitabında ortaya konulmuştur. Bir envanter olarak sunulması ve bir ölçüm aracı olarak kullanılması ise 1970'lere kadar uzanır.( https://www.discakademi.com, Erişim: 12.04.2019)

Harvard Üniversitesi'nde doktorasını gelişmekte olan psikoloji konusunda yapan Marston, 'Normal İnsanların Duyguları' kitabında şartları belirlenmiş herhangi bir ortamda gözlemleyebileceği normal davranışları inceledi. Kişiliğimi oluşturan unsurların içsel ve doğuştan olduğu kadar çevreden de kaynaklandığına inanıyordu. (www.discprofile.com, Erişim: 21.04.2019)

Marston, davranışsal özelliklern 4 kategoriye ayrılabileceğini söyler. Aynı kategori içinde yer alan insanlar bu kategori için ortak gözlemlenen davranış özellikleri gösterirler. Marston, bu kategorizasyonu ortaya koyabilecek bir yöntem oluşturdu. DISC kısaltması altında bu ana karakter tiplerini aşağıdaki şekilde göstermiştir. (https://www.discakademi.com, Erişim: 12.04.2019) 


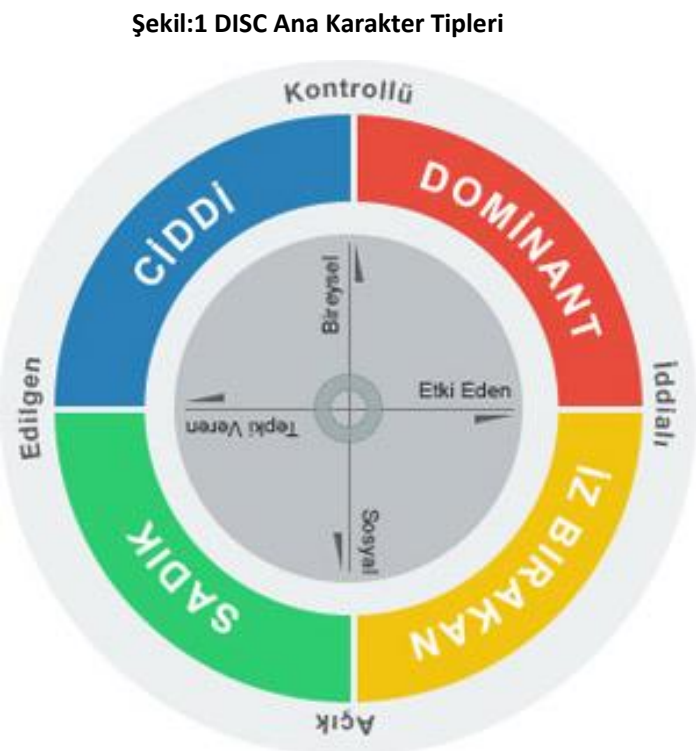

Ana karakter tiplerimizin özellikleri ise;

D (Dominant): Dominant profilde olan kişiler baskın, kararlarında net, risk almayı seven kişilerdir. Bu özelliklerinden dolayı açık sözlü ve harekete geçebilen kişilerdir. Risk alma ve karar verme yetkisini bulunduran güç ve otorite karşııında motive olurlar. Takımda idareci konumunda olurlar. Aynı anda birden fazla iş yapabilen, rutinden hoşlanmazlar.

I (íz Bırakan): Samimiyet, takdir, popülerlik ve onaylanma I profiline sahip bir kişiyi motive eder. Kurallar ve düzenden uzak, rahat bir çalışma ortamında bulunmayı, detaylarla başkalarıın ilgilenmesini isterler. Yaratıcı, problem çözücüdür. Takımı cesaretlendirir, amaca ulaşmaları için motive eder. Olumlu bir espri anlayışı vardır ve tartışmaları barış ile çözer. Sonuçlardan çok, popüler olmakla ilgilenir ve detaylarla uğraşmak istemez. Detaylarla ilgilenmez ,sadece ilgisini çekerse dinlemeye yatkındır.

S (Sadık): S profile sahip kişiler iyi bir dinleyici, sahiplenici ve arkadaş canlısı bir yapıya sahiptir. Anlayışlı, arkadaş canlısı ve diğer insanların hatalarına anlayış gösterebilen insanlardır. Bağlıık ve güvenebilme duygusu S profilinin özelliklerini taşıyan kişilerde oldukça önemli bir unsurdur, kendilerini güvende hissetmek isterler. Prosedürde veya hayat biçiminde ani değişikliklerin olmamasını tercih ederler. Saygın, güvenilir ve sadık bir takım çalışanıdır. Otoriteye uyumludur. İyi bir dinleyici, sabırlı ve empati sahibidir. Tartışmalarda, uzlaşma sağlamada başarılıdır. Değişime dirençli bir yapısı vardır ve bu değişime uyum sağlama süreci zaman alır. Kin besler ama eleştirmekten kaçınır. Öncelik belirlemede zorluk yaşar. Güven olgusuna önem veren S profili, güven kaybetmekten oldukça çekinir.

C (Ciddi): Kesin, analitik, dürüst, dikkatli bir karakter özelliklerine sahip olan C profili, araştıran, titiz, yüksek standartları olan, sistemli bir yapıya sahiptir. Yüksek kalite standartları, detaylı görevler verilmesi çalışma ortamında motive olmasını sağlar. Mantıkı bilgi düzenleme ve detaylara odaklanarak çalışmayı tercih ederler. İ̧ konsantrasyonu yoğundur. Dikkatli ve soğukkanlı bir şekilde işi sürdürürler. Detaycıdır, en ince ayrıntılara dikkat ederek bilgiyi derler, kritiğini yapar. Olay ve ilişkilerde keskin sınırlara intiyaç duyar. Denenmiş yöntem ve prosedürlerden vazgeçmek istemezler. Detaylara fazlasıyla önem verir. Duygularıı ifade etmekte zorlanır ve tartışmaktansa pes etmeyi tercih eder. Eleştirilmekten çekinir ve rahatsızlık duyarlar.

Illk kez ABD ordusu tarafından I. Dünya Savaşı'nda kullanılan ve hangi askerlerin "savaş bunalımından" etkilenebileceğini belirlemeyi amaçlayan kişilik testleri bugün 500 milyon dolarlık hacme erişen ve yılda yüzde 10-15 büyüyen bir endüstri haline geldi. Her yıl milyonlarca çalışan eleman seçimi, işbirliğini ve takım, çalışmasını güçlendirme ve tatmin edici kariyer yolları oluşturma anlamında bu testlerden geçiyor. (https://hbrturkiye.com.Erişim.14.04.2019.)

\section{BULGULAR}

\subsection{Doğal Karakter Analizi}

Iş başvurularında ve çalışan personellere yapılan kişilik envanteri testleri ile doğal karakteri analizi sonucunda baskın olarak "Ciddi" ana karakteri ortaya çıkmıştır. Ortalama 620 kişi ile yapılan bu çalışmada 389 kişinin 'Ciddi' ana karakter tipini taşıdığı görülmüştür. 'Sadık' ana karakter tipini taşıyan kişi sayısının ise 120 olduğu ortaya çıkmıştır. Bu iki ana karakter tipini sırasıyla 57 kişi ile 'izz Bırakan' ve 52 kişi ile 'Dominant' ana karakter tipi takip etmektedir. 
Grafik 1: Doğal Karakter Analizi

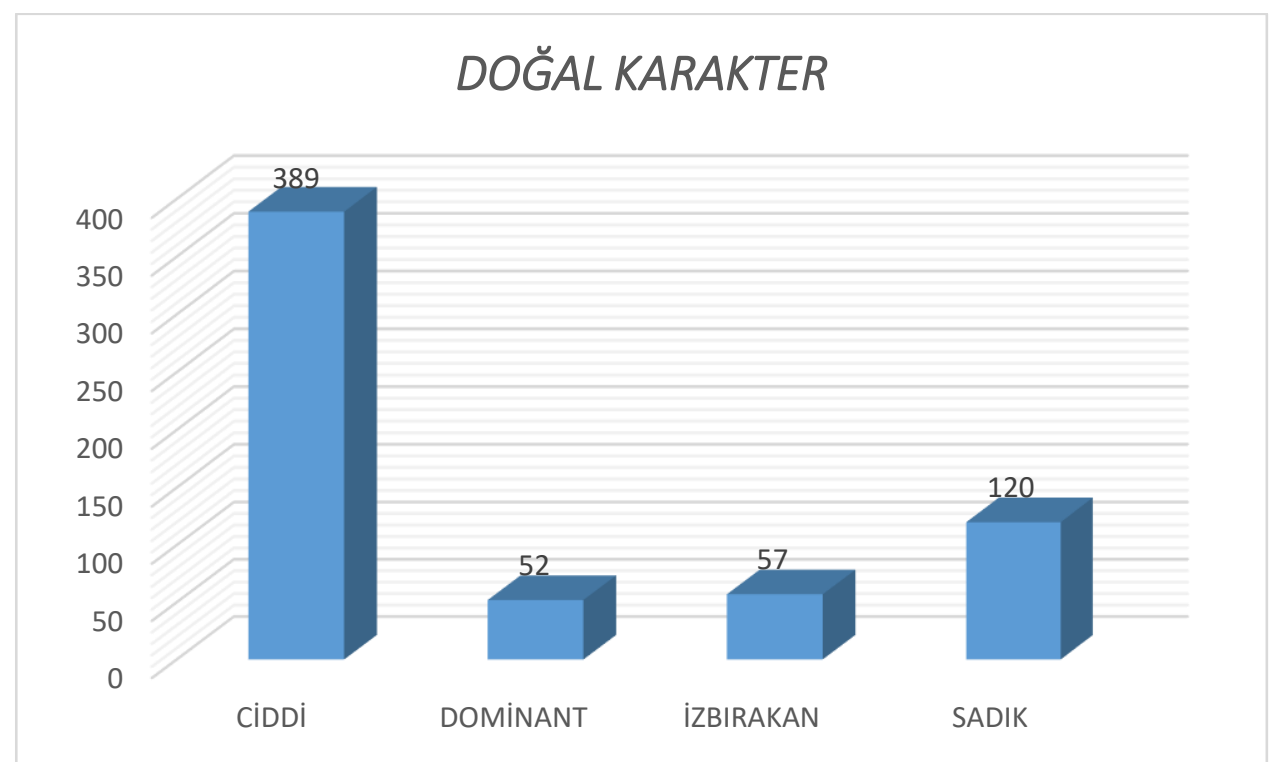

\subsection{Ortama Uyarlanmış Karakter Analizi}

İş başvurularında ve çalışan personellere yapılan kişilik envanteri testleri ile ortama uyarlanmış karakter analizi sonucunda baskın olarak "Ciddi” ana karakteri ortaya çıkmıştır. 81 kişi 'Sadık' ana karakter tipinde olup, 48 kişi 'İz Bırakan' ve 19 kişinin de 'Dominant' karakterde olduğu görüşmüştür.

\section{Grafik 2: Ortama Uyarlanmış Karakter Analizi}

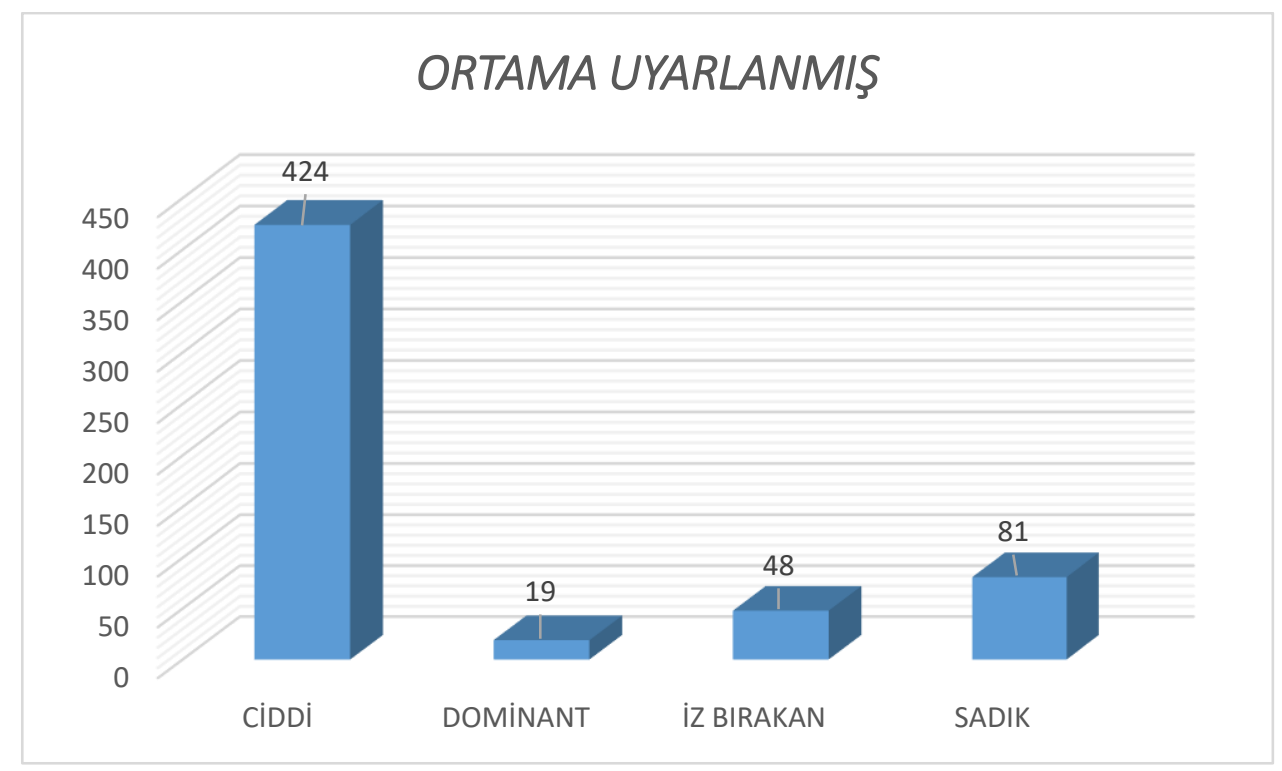

\subsection{Stres Seviyesi Analizi}

Yapılan testler sonucunda iş başvurusunda bulunan ve halen çalışmakta olan personellerin stres seviyesi 'Çok Düşük', 'Düşük', 'Ortalama', 'Yüksek', 'Yüksek (İ̧̧ Ortamı Kaynaklı' ve 'Çok Yüksek' olarak ölçülmüştür. Bu araştırmada ortalama 240 kişinin 'Düşük' stres seviyesinde oldukları görülmüştür. 
Grafik 3: Stres Seviyesi Analizi

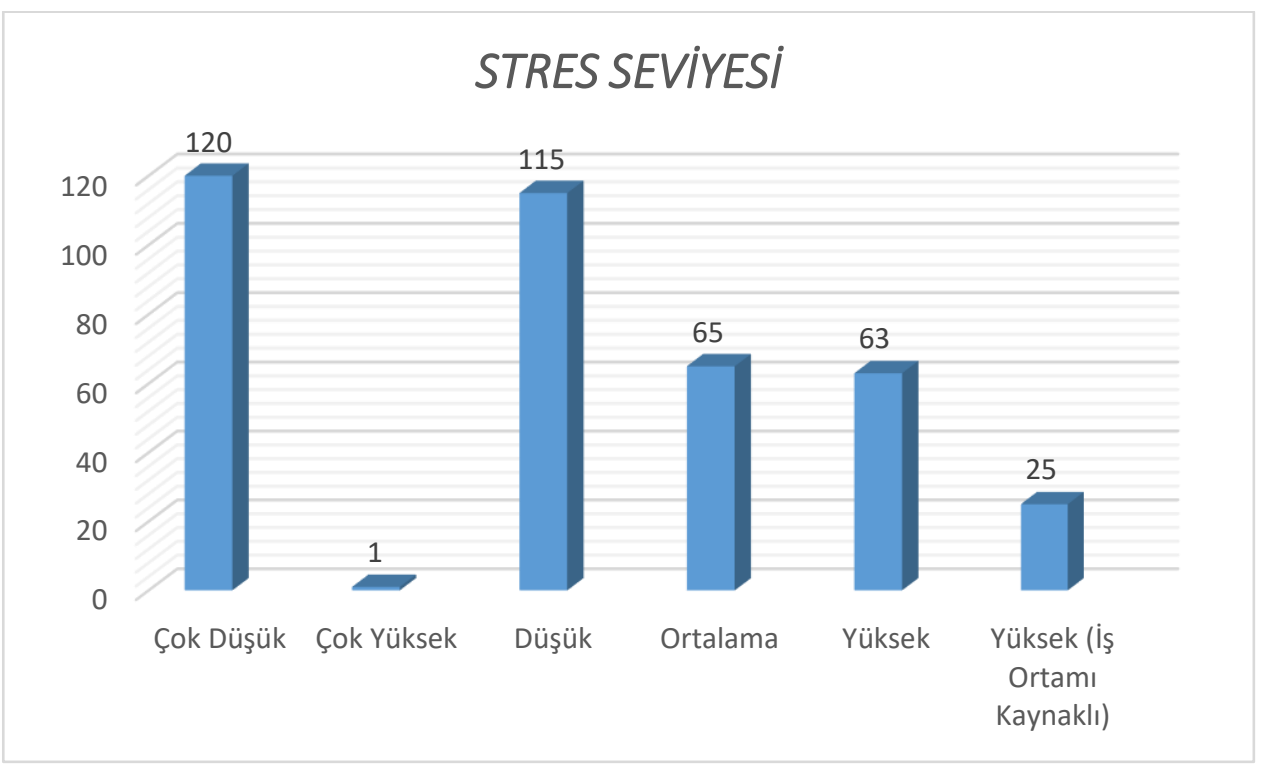

\section{SONUÇ}

DISC Kişilik Envanteri yöntemiyle; iş başvurusu yapan ve halen çalışmakta olan personelin, bireysel tutumlarının ve iş ortamındaki davranışlarının, örgüt kültürüne uyumu açısından değerlendirilerek kişilerin doğru pozisyona yerleştirilmesi amaçlanmaktadır. DıSC Kişilik Envanteri ile eğitim ihtiyaç analizi doğrultusunda kişilere ihtiyaç duydukları eğitimlerin verilmesi ve kariyer haritaları oluşturulması açısından önemli bir veri sağlamaktadır. İşe alım aşamasında ve mevcut işgören havuzu üzerinden yapılan kişilik envanteri testleri sonucunda ortama uyarlanmış karakter analizi ile "Ciddi” ana karakter tipinin \% 74 oranında, "Sadık” ana karakter tipinin \% 14 oranında, "Iz Bırakan” ana karakter tipinin \% 8 oranında, "Dominant" ana karakter tipinin ise \% 4 oranında olduğu sonucuna varılmıştır. Araştırma sonucunda \% 74 oranında ortaya çıkan "Ciddi" ana karakter tipi, lojistik sektörü içerisinde yer alan işgücü hakkında önemli bir ipucu vermektedir. Analitik, güvenilir, özenli karakter özellikleri gösteren bu ana karakter grubu, sorgulayıcı, detaylara yoğunlaşan, sistematik bir düşünce yapısına sahiptir. Bu durum lojistik sektöründe yapılan işler ile uyum sağlamaktadır. Bu şekilde yüksek müşteri memnuniyeti gerektiren durumlarda iş ortamında sürekli motivasyon gösterilmesini sağlar. Bu çalışma sonucunda kişilik envanter testleri uygulanan adaylardan "Ciddi" ana karakter tipi olanlardan bir havuz oluşturulması fayda sağlayacaktır. Bu aday havuzu, aynı zamanda mülakatlarda önemli bir veri kaynağıdır. Pozisyona uygun adaylar aranırken, "Ciddi" ana karakter tipine sahip adaylar, oluşturulan havuz kapsamında bulunarak zaman ve test maliyeti açısından tasarruf sağlayacaktır.

\section{KAYNAKÇA}

Acar, Z. ve Köseoğlu, M. (2016). Lojistik Yaklaşımıyla Tedarik Zinciri Yönetimi, İstanbul.

Alkan, M. ve Erdal, M. (2007). Lojistik ve Dış Ticaret Sözlüğü. UTiKAD; Keskin (2011). Lojistik ve Tedarik Zinciri Yönetimi: Geçmişi, Değişimi, Bugünü, Geleceği (4.b). Ankara, Nobel Akademik Yayıncılık.

Bayat, B. (2008). İnsan Kaynakları Yönetiminin Stratejik Niteliği. Gazi Üniversitesi İktisadi ve İdari Bilimler Fakültesi Dergisi, 10(3), 1-25.

Council of Supply Chain Management Professionals

https://cscmp.org/CSCMP/Educate/SCM Definitions and Glossary of Terms/CSCMP/Educate/SCM Definitions and Glossary of Terms. aspx?hkey=60879588-f65f-4ab5-8c4b-6878815ef921, Erişim: 14.04 .2019

DISC Akademi Eğitim ve Yazııım A.Ş. www.discakademi.com , Erişim: 14.04.2019

Personality Profile Solutions, LLC. www.discprofile.com, Erişim: 21.04.2019

Gümüş, Y. (2009). Lojistik Faaliyetlerinin Rekabet Stratejileri ve İşletme Karı ile Olan İlişkisi, Muhasebe ve Finansman Dergisi, 97-113.

Kişilik Testlerinin Kısa Tarihi, Harvard Business Review Türkiye www.hbrturkiye.com , Erişim 14.04.2019

Küçük, O. (2011). Stok Yönetimi. Ankara, Seçkin Yayıncılık, s.129

Sezen, B. ve Gök, M.Ş. (2004). Logistics Management and Just in Time Manufacturing Systems. İnternational Logistics Congress (s.4). İzmir, Dokuz Eylül Üniversitesi. 
Sadullah, Ö., Özçelik, O., Uyargil, C., Acar, C., Dündar, G., Ataay, I., Adal, Z. ve Tüzüner, L. (2013). İnsan Kaynakları Yönetimi, Istanbul,Yenilenmiş 6. Baskı, Beta.

Tunçer, P, (2012). Değişen İnsan Kaynakları Yönetimi Anlayışında Kariyer Yönetimi. Ondokuz Mayıs Üniversitesi Eğitim Fakültesi Dergisi, 31(1). 203-233.

Türk Dil Kurumu Sözlüğü, www.tdk.gov.tr , Erişim: 12.04.2019

Yarımkaya, A.,(2011) İnsan Kaynakları Yönetimi, İstanbul, İstanbul Sanayi Odası (iSO). 